FedUni ResearchOnline https://researchonline.federation.edu.au

This is the peer-reviewed version of the following article:

Masoum, A., Hashemnia, S., Abu-Siada, A., Masoum, M., Islam, S. (2017)

Online transformer internal fault detection based on instantaneous voltage and current measurements considering impact of harmonics, IEEE

Transactions on Power Delivery, 32(2), p. 587-598.

Which has been published in final form at:

https://doi.org/10.1109/TPWRD.2014.2358072

Copyright (C) 2014 IEEE. Personal use of this material is permitted. Permission from IEEE must be obtained for all other uses, in any current or future media, including reprinting/republishing this material for advertising or promotional purposes, creating new collective works, for resale or redistribution to servers or lists, or reuse of any copyrighted component of this work in other works. 


\title{
Online Transformer Internal Fault Detection Based on Instantaneous Voltage and Current Measurements Considering Impact of Harmonics
}

\author{
Ali S. Masoum, Student Member, IEEE, Naser Hashemnia, Student Member, IEEE, A. Abu-Siada, Senior Member, \\ IEEE, Mohammad A.S. Masoum, Senior Member, IEEE, Syed M. Islam, Senior Member, IEEE
}

\begin{abstract}
This paper investigates the performance of a recently proposed online transformer internal fault detection technique and examines impact of harmonics through detailed nonlinear simulation of a transformer using three-dimensional finite element modelling. The proposed online technique is based on considering the correlation between the instantaneous input and output voltage difference $(\Delta V)$ and the input current of a particular phase as a finger print of the transformer that could be measured every cycle to identify any incipient mechanical deformation within power transformers. To precisely emulate real transformer operation under various winding mechanical deformations, a detailed three-dimensional finite-element model is developed. Detailed simulations with (non)sinusoidal excitation are performed and analysed to demonstrate the unique impact of each fault on the $\Delta V$-I locus. Impact of harmonic order, magnitude and phase angle is also investigated. Furthermore, practical measurements have been performed to validate the effect of winding short circuit fault on the proposed $\Delta V$-I locus without and with the impact of system harmonics.
\end{abstract}

Index Terms- Online fault detection, condition monitoring, nonlinear power transformer, finite-element and harmonics.

\section{INTRODUCTION}

$\mathrm{P}$ ower transformers are vital links and one of the most critical and expensive assets in electrical power systems. The majority of in-service power transformers have already exceeded their expected rated life as they were mostly installed prior to 1980 [1]. This poses a significant risk for utilities as impacts of in-service transformer failures can be catastrophic. Furthermore, the day-by-day increase in load demand, global trend to develop smart grids and the growing number of nonlinear loads such as smart appliances and electric vehicles will further increase the likelihood of non-sinusoidal transformer operation and failures. Therefore, it is essential to adopt simple, reliable and accurate diagnostic tools to determine the current state, detect incipient faults and estimate remaining life of the existing in-service power transformers in order to prevent failures, decrease maintenance cost and improve reliability of the power systems [2-4]. Conventional transformer windings are made of copper strands covered with paper or continuously transposed coated copper strands with an overall paper covering, while more recent technologies use soft or hard pressboard for interlayer, inter-turn, end insulation and winding cylinders [5]. Aging of transformer paper and pressboard which is a function of temperature, moisture and oxygen will reduce the dielectric strength of the insulation due to the presence of contaminants including oxidation products from oil and moisture. This will reduce insulation tensile

A.S. Masoum is a Graduate Electrical Engineer at Western Power, Perth WA, Australia. N. Hashemnia, A. Abu-Siada, M.A.S. Masoum and S. Islam are with Department of Electrical and Computer Engineering, Curtin University, WA, Australia. Emails: ali.sherkatmasoum@postgrad.curtin.edu.au, naser. hashemnia@postgrad.curtin.edu.au, a.abuSiada@curtin.edu.au,m.masoum@ curtin.edu.au,s.islam@curtin.edu.au. strength and eventually results in losing clamping pressure leading to winding deformation. Furthermore, due to thermal stress that in-service transformer exhibits and because of short circuit faults, oil and paper decomposition takes place evolving subsequent gases that dissolve in oil, reduce its dielectric strength and may lead to partial discharge or sustained arcing if a proper corrective action is not taken [6]. Although a transformer with minor winding deformation can continue to work normally, its capability to withstand further faults is significantly reduced. Therefore, it is vital to continuously monitor and quickly detect winding deformation as it is one of the first and fundamental precursors to a decline in transformer condition. Physical inspection of core and winding deformation is not recommended since it requires removal of oil and exposure of insulation to air which increases the transformer failure risk. The most common and widely accepted approach to detect transformer winding deformations, core and clamping structure is the frequency response analysis (FRA) [7]. FRA is an offline test based on the measurement of the impedance, admittance or transfer function of a particular phase as a function of a wide frequency range which is used as a transformer fingerprint that can be compared with its previous signatures to detect any winding displacements [8]. Although FRA is a powerful diagnostic tool for detecting winding deformation, its offline nature and reliance on graphical analysis are considered as the main drawbacks [9]. A practical and simple online transformer internal fault detection technique has recently been proposed $[6,10]$. This online technique is based on considering the correlation of the transformer input and output instantaneous voltage difference $\left(\Delta \mathrm{V}=\mathrm{v}_{1}(\mathrm{t})-\mathrm{v}_{2}(\mathrm{t})\right)$ and input current $(\mathrm{I}=\mathrm{i}(\mathrm{t}))$ as a transformer fingerprint that could be measured every cycle at the network power frequency and compared with the previous locus to identify any incipient changes within the internal mechanical structure of the transformer. While this online approach is immature and its performance and accuracy have not been thoroughly validated, it looks very promising and deserves further research and investigation. In this paper, a detailed three-dimensional finite element transformer model is developed to validate the performance of the proposed $\Delta \mathrm{V}$-I fault detection online technique [6] and also to investigate its performance under non-sinusoidal operating conditions. As it is difficult to implement faults on practical transformer without harming it, a transformer nonlinear finite-element model is used to readily emulate various transformer internal physical faults. Power transformer is simulated for (non)sinusoidal operations subjected to four types of internal faults and the corresponding $\Delta \mathrm{V}$-I loci are generated. Simulations and laboratory measurements are used to validate the online detection approach by investigating the impacts of various fault types and levels, as well as harmonic orders and magnitudes on the $\Delta \mathrm{V}$-I locus. Simulations are performed using Simplorer and Maxwell finite element software packages [11]. 


\section{Online Internal Fault Detection TeChnique CONSIDERING HARMONICS}

The online internal fault detection technique presented in [6] is based on the construction of a locus diagram relating a transformer input current on the x-axis and the difference between the input and output voltages on the y-axis. The relationship relating the above parameters in the presence of harmonics can be derived based on the single-phase transformer equivalent circuit of Fig. 1 using superposition.

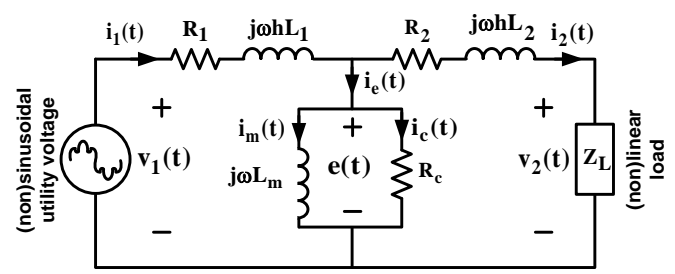

Fig. 1. Equivalent circuit of single-phase transformer with (non) sinusoidal excitation and (non)linear loading.

\section{A. Transformer $\Delta V^{(1)}-I^{(1)}$ Locus at Fundamental Frequency}

Cartesian formula relating $\mathrm{x}=\mathrm{I}^{(1)}=\mathrm{i}_{1}^{(1)}(\mathrm{t})=\mathrm{I}_{1}^{(1)} \sin \left(\omega \mathrm{t}-\varphi^{(1)}\right)$ and $\mathrm{y}=\Delta \mathrm{V}^{(1)}=\mathrm{v}_{1}^{(1)}(\mathrm{t})-\mathrm{v}_{2}^{(1)}(\mathrm{t}) \approx \mathrm{V}^{(1)} \sin \left(\omega \mathrm{t}+\delta^{(1)}\right)-\mathrm{V}^{(1)} \sin (\omega \mathrm{t})$ $=2 \mathrm{~V}^{(1)} \cos \left(\omega \mathrm{t}+\delta^{(1)} / 2\right) \sin \left(\delta^{(1)} / 2\right)$ at fundamental frequency is obtained by eliminating $\omega \mathrm{t}$. The simplified formula is [6]:

$\mathrm{A}^{(1)} \mathrm{x}^{2}+\mathrm{B}^{(1)} \mathrm{xy}+\mathrm{C}^{(1)} \mathrm{y}^{2}+\mathrm{D}^{(1)}=0$

where $\quad \mathrm{A}^{(1)}=\left[\left(2 \mathrm{~V}^{(1)} \sin \left(\delta^{(1)} / 2\right)\right]^{2}, \mathrm{~B}^{(1)}=\mathrm{V}^{(1)} \mathrm{I}^{(1)} \sin \left(\delta^{(1)} / 2\right) \sin \left(\varphi^{(1)}\right.\right.$ $\left.+\delta^{(1)} / 2\right), \mathrm{C}^{(1)}=\left(\mathrm{I}^{(1)}\right)^{2} \quad$ and $\mathrm{D}^{(1)}=\left[2 \mathrm{~V}^{(1)} \mathrm{I}^{(1)} \sin \left(\delta^{(1)} / 2\right) \sin \left(\varphi^{(1)}+\right.\right.$ $\left.\left.\delta^{(1)} / 2\right)\right]^{2}-\left[2 \mathrm{~V}^{(1)} \mathrm{I}^{(1)} \sin \left(\delta^{(1)} / 2\right)\right]^{2}$. Since, $\quad\left(\mathrm{B}^{(1)}\right)^{2}-4 \mathrm{~A}^{(1)} \mathrm{C}^{(1)}=-16$ $\left(\mathrm{I}^{(1)}\right)^{2}\left(\mathrm{~V}^{(1)}\right)^{2} \sin ^{2}\left(\delta^{(1)} / 2\right) \cos ^{2}\left(\varphi^{(1)}+\delta^{(1)} / 2\right)$ is a negative term regardless the values of $\mathrm{I}^{(1)}, \mathrm{V}^{(1)}, \delta^{(1)}$ and $\varphi^{(1)}$, the Cartesian relationship of Eq. 1; $\Delta \mathrm{V}^{(\mathbf{1})}-\mathrm{I}^{(\mathbf{1})}$ locus, represents an ellipse as shown in Fig. 2(a).

\section{B. Transformer $\Delta V^{(h)}-I^{(h)}$ Locus at Harmonic Frequencies}

At the $h^{\text {th }}$ harmonic frequency, the Cartesian equation relating $\mathrm{x}=\mathrm{I}^{(\mathrm{h})}=\mathrm{i}_{1}^{(\mathrm{h})}(\mathrm{t})=\mathrm{I}_{1}^{(\mathrm{h})} \sin \left(\mathrm{h} \omega \mathrm{t}-\varphi^{(\mathrm{h})}\right)$ and $\mathrm{y}=\Delta \mathrm{V}^{(\mathrm{h})}=\mathrm{v}_{1}^{(\mathrm{h})}(\mathrm{t})$ $-\mathrm{v}_{2}^{(\mathrm{h})}(\mathrm{t}) \approx \mathrm{V}^{(\mathrm{h})} \sin \left(\mathrm{h} \omega \mathrm{t}+\delta^{(\mathrm{h})}\right)-\mathrm{V}^{(\mathrm{h})} \sin (\mathrm{h} \omega \mathrm{t})=2 \mathrm{~V}^{(\mathrm{h})} \cos (\mathrm{h} \omega \mathrm{t}$ $\left.+\delta^{(\mathrm{h})} / 2\right) \sin \left(\delta^{(\mathrm{h})} / 2\right)$ is obtained by eliminating $h \omega t$ as below:

$A^{(h)} x^{2}+B^{(h)} x y+C^{(h)} y^{2}+D^{(h)}=0$

where $\mathrm{A}^{(\mathrm{h})}=\left[\left(2 \mathrm{~V}^{(\mathrm{h})} \sin \left(\delta^{(\mathrm{h})} / 2\right)\right]^{2}, \mathrm{~B}^{(\mathrm{h})}=\mathrm{V}^{(\mathrm{h})} \mathrm{I}^{(\mathrm{h})} \sin \left(\delta^{(\mathrm{h})} / 2\right) \sin \left(\varphi^{(\mathrm{h})}\right.\right.$ $\left.+\delta^{(\mathrm{h})} / 2\right), \quad \mathrm{C}^{(\mathrm{h})}=\left(\mathrm{I}^{(\mathrm{h})}\right)^{2}$ and $\mathrm{D}^{(\mathrm{h})}=\left[2 \mathrm{~V}^{(\mathrm{h})} \mathrm{I}^{(\mathrm{h})} \sin \left(\delta^{(\mathrm{h})} / 2\right) \sin \left(\varphi^{(\mathrm{h})}\right.\right.$ $\left.\left.+\delta^{(\mathrm{h})} / 2\right)\right]^{2}-\left[2 \mathrm{~V}^{(\mathrm{h})} \mathrm{I}^{(1)} \sin \left(\delta^{(\mathrm{h})} / 2\right)\right]^{2}$. Since, $\left(\mathrm{B}^{(\mathrm{h})}\right)^{2}-4 \mathrm{~A}^{(\mathrm{h})} \mathrm{C}^{(\mathrm{h})}=$ $-16\left(\mathrm{I}^{(\mathrm{h})}\right)^{2}\left(\mathrm{~V}^{(\mathrm{h})}\right)^{2} \sin ^{2}\left(\delta^{(\mathrm{h})} / 2\right) \cos ^{2}\left(\varphi^{(\mathrm{h})}+\delta^{(\mathrm{h})} / 2\right) \quad$ is negative regardless of the $\mathrm{I}^{(\mathrm{h})}, \mathrm{V}^{(\mathrm{h})}, \delta^{(\mathrm{h})}$ and $\varphi^{(\mathrm{h})}$ values, the $\Delta \boldsymbol{V}^{(\boldsymbol{h})}-\boldsymbol{I}^{(\boldsymbol{h})}$ Cartesian relationship (Eq. 2) also represents an ellipse.

\section{Transformer $\Delta$ V-I Locus for Non-Sinusoidal Operation}

Assuming a linear transformer model (Fig. 1), the concept of superposition can be applied to Eqs. 1 and 2. Therefore, the Cartesian relation for a non-sinusoidal transformer excitation with fundamental and $\mathrm{h}^{\text {th }}$ harmonic components will be the superposition of two ellipses $\left(\Delta \mathrm{V}^{(\mathbf{1 + h})}-\mathrm{I}^{(\mathbf{1 + h})}\right)$. The ellipses will have different radiuses on the $\mathrm{x}$ and $\mathrm{y}$ axis as most standards limit the harmonic voltage distortion to five percent of the fundamental component. Fig. 2(b) illustrates formation of the distorted ellipse locus with minor loops. The shape, magnitude and number of minor loops depend on the harmonic order, magnitude and phase.

\section{Graphical Representation of Fault Detection Approach}

The online fault detection approach is graphically demonstrated in Fig. 2(a) for sinusoidal excitation with a lagging power factor (PF) of 0.8 where the instantaneous values of $\mathrm{y}=\Delta \mathrm{V}^{(\mathbf{1})}$ and $\mathrm{x}=\mathrm{I}^{(\mathbf{1})}$ are measured at a particular time to calculate the corresponding point on the $\Delta \mathrm{V}^{(\mathbf{1})}-\mathrm{I}^{(\mathbf{1})}$ locus (Eq. 1 ). The phase shift between primary and secondary voltages $\delta^{(\mathbf{1})}$ is relatively small and its impact on the proposed locus is insignificant and can be neglected [6]. Furthermore, the phase shift $\varphi^{(\mathbf{1})}$ between primary current and secondary voltage is almost equal to the load impedance phase angle since phase shift between primary and secondary currents is negligible [6].

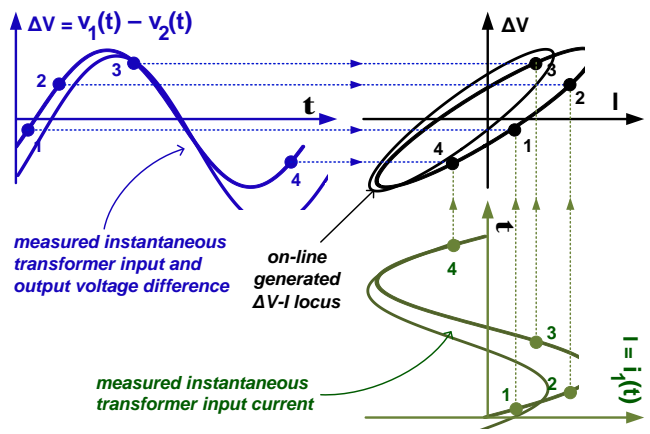

(a)

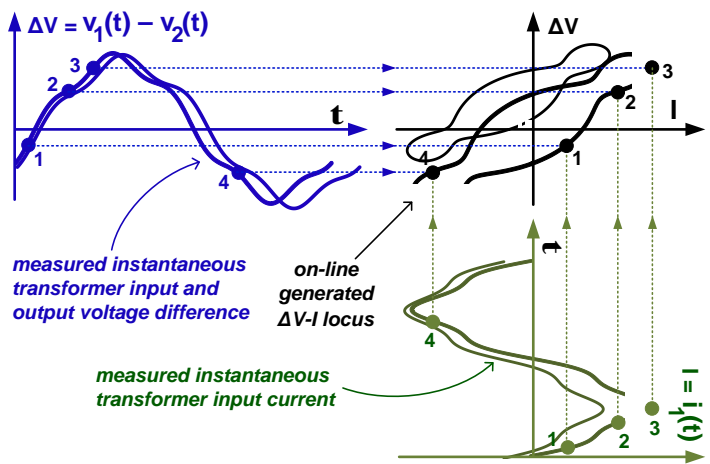

(b)

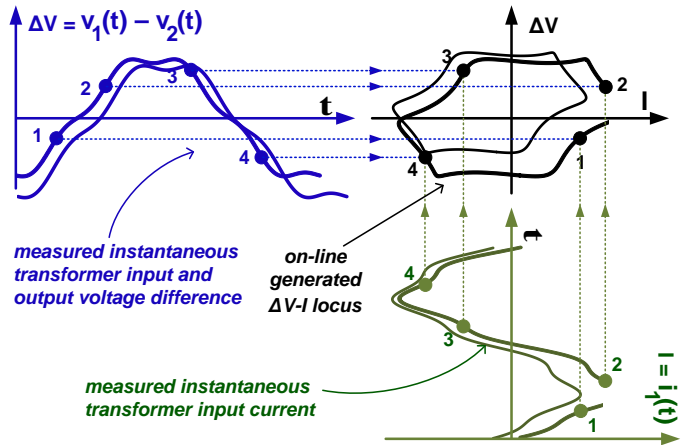

(c)

Fig. 2. Graphical illustration for the formation of transformer $\Delta$ V-I locus by plotting instantaneous $\Delta \mathrm{v}(\mathrm{t})$ versus $\mathrm{i}_{1}(\mathrm{t})$ with sinusoidal (a) and non-sinusoidal (b-c) excitations. 
Figs. 2(b) and (c) demonstrate the formation of the $\Delta \mathrm{V}^{(1+5)}$ $\mathrm{I}^{(1+5)}$ locus for a non-sinusoidal excitation consisting of fundamental and $10 \%$ of $5^{\text {th }}$ harmonic voltage with harmonic phase angle of $0^{\circ}$ and $180^{\circ}$, respectively. In these cases, the shapes of locus are distorted ellipse with peaky and flat minor loops (Eq. 2). It is worth mentioning that the $\Delta \mathrm{V}$-I locus is generated by plotting the instantaneous values of $\Delta v(t)=v_{1}(t)-v_{2}(t)$ versus the instantaneous values of $i_{1}(t)$ at a particular time step. Therefore, the extreme limits of both I ( $\mathrm{x}$ axis) and $\Delta \mathrm{V}$ (y axis) swap between their corresponding maximum positive and minimum negative limits as illustrated in Fig. 2.

\section{Transformer Magnetic And Electric Models}

The conventional transformer equivalent distributedparameters electrical model [8] is shown in Fig. 3(a). For the analyses and simulations of this paper, the detailed threedimensional finite-element nonlinear model comprising transformer magnetic and electric components of a singlephase, shell-type transformer as shown in Fig. 3(b) is developed using the Maxwell/Simplorer finite element software [11] based on the transformer physical dimensions as given in the Appendix. The transformer equivalent electrical circuit parameters including self/mutual inductance, resistance and capacitance are obtained by solving the three-dimensional transformer model in magneto-static and electro-static solvers using Maxwell's equations as will be briefly elaborated below.

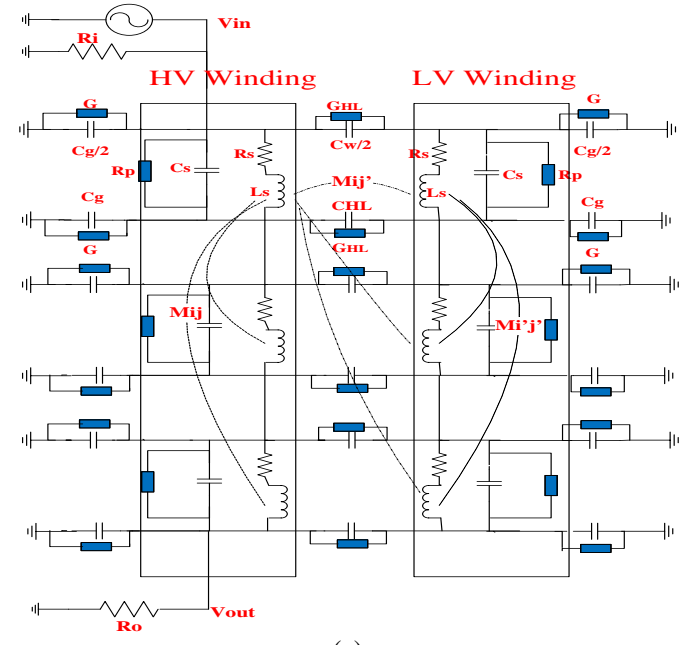

(a)

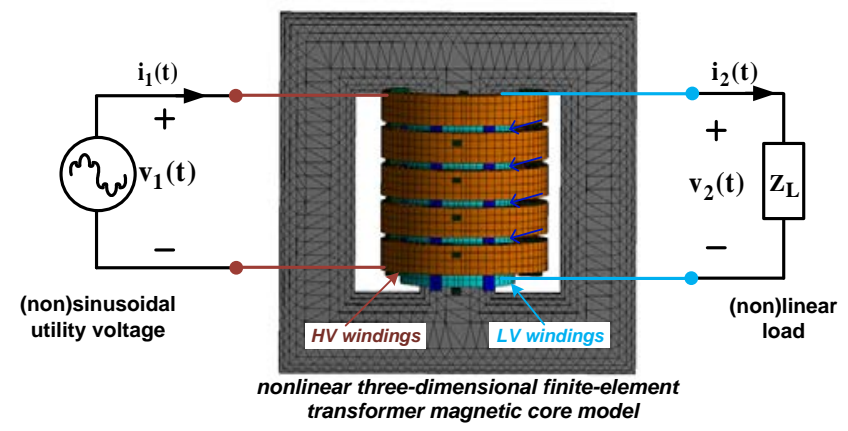

(b)

Fig. 3. Transformer models for internal fault emulation; (a) equivalent linear distributed-parameters electrical model [6, 8], (b) complte nonlinear finiteelemnet model (Appendix) with magnetic and electric circuits, (non)siunsoidal excitation and linear load implemented for the analysis of this paper using the Maxwell/Simplorer software package [11].

Because of its frequency dependency, winding resistance is calculated using the eddy current solver. The winding resistance $\left(R_{i i}\right)$ and self-inductance $\left(L_{i i}\right)$ of the $i^{\text {th }}$ section of a winding (Fig. 4) can be calculated using real $(\operatorname{Re}\{\})$ and imaginary $(\operatorname{Im}\{\})$ components of the energy [12-13]:

$$
\begin{aligned}
& \mathrm{R}_{\mathrm{ii}}=2 \omega \operatorname{Re}\left\{\mathrm{j} \mathrm{W}_{\text {mag,i,i }}\right\} / \mathrm{I}_{\mathrm{i}}^{2} \\
& \mathrm{~L}_{\mathrm{ii}}=2 \operatorname{Im}\left\{\mathrm{j} \mathrm{W}_{\text {mag,i,i }}\right\} / \mathrm{I}_{\mathrm{i}}^{2}
\end{aligned}
$$

where $\omega$ is the angular frequency and $W_{\text {mag,i,i }}$ is the produced magnetic energy when current $I_{i}$ is applied to the $i^{\text {th }}$ winding. The resistance $\left(R_{i j}\right)$ and mutual inductance $\left(M_{i j}\right)$ between $i^{\text {th }}$ and $j^{\text {th }}$ winding sections is:

$$
\begin{aligned}
& \mathrm{R}_{\mathrm{ij}}=\left(\mathrm{w}_{\mathrm{i}} \mathrm{n}_{\mathrm{j}} \operatorname{Im}\left\{\mathrm{W}_{\text {mag,i,j }}\right\}-0.5 \mathrm{R}_{\mathrm{ii}} \mathrm{I}_{\mathrm{i}}^{2}-0.5 \mathrm{R}_{\mathrm{jj}} \mathrm{I}_{\mathrm{j}}^{2}\right) / \mathrm{I}_{\mathrm{i}} \mathrm{I}_{\mathrm{j}} \\
& \mathrm{M}_{\mathrm{ij}}=\left(\mathrm{n}_{\mathrm{i}} \mathrm{n}_{\mathrm{j}} \operatorname{Re}\left\{\mathrm{W}_{\text {mag, }, \mathrm{i}, \mathrm{j}}\right\}-0.5 \mathrm{~L}_{\mathrm{ii}} \mathrm{I}_{\mathrm{i}}^{2}-0.5 \mathrm{~L}_{\mathrm{jj}} \mathrm{I}_{\mathrm{j}}^{2}\right) / \mathrm{I}_{\mathrm{i}} \mathrm{I}_{\mathrm{j}}
\end{aligned}
$$

where $W_{\text {mag,i,j }}$ is the total magnetic energy when $I_{\mathbf{i}}$ and $I_{\mathbf{j}}$ are simultaneously applied to $\mathrm{i}^{\text {th }}$ and $\mathrm{j}^{\text {th }}$ windings, respectively. The relationship between the flux linkages $(\lambda)$ and currents is given in terms of inductance matrix (Fig. 4):

$$
\left[\begin{array}{l}
\lambda_{1} \\
\lambda_{2} \\
\lambda_{3}
\end{array}\right]=\left[\begin{array}{lll}
\mathrm{L}_{11} & \mathrm{~L}_{12} & \mathrm{~L}_{13} \\
\mathrm{~L}_{21} & \mathrm{~L}_{22} & \mathrm{~L}_{23} \\
\mathrm{~L}_{31} & \mathrm{~L}_{31} & \mathrm{~L}_{33}
\end{array}\right]\left[\begin{array}{l}
\mathrm{I}_{1} \\
\mathrm{I}_{2} \\
\mathrm{I}_{3}
\end{array}\right]
$$

The electrostatic energy $\mathrm{W}_{\mathrm{el}}=0.5 \mathrm{CV}^{2}$ is used to calculate capacitances between the disks $\left(\mathrm{C}_{\mathrm{ii}}\right)$ and the windings $\left(\mathrm{C}_{\mathrm{ij}}\right)$ :

$\mathrm{C}_{\mathrm{ii}}=2 \operatorname{Re}\left\{\mathrm{W}_{\mathrm{el}, \mathrm{i}, \mathrm{i}}\right\} / \mathrm{V}_{\mathrm{i}}^{2}$

$C_{i j}=\left(\operatorname{Re}\left\{W_{e l, i, j}\right\}-0.5 C_{i i} V_{i}^{2}-0.5 C_{j j} V_{j}^{2}\right) / V_{i} V_{j}$

A capacitance matrix represents the charge coupling within a group of conductors. Given a ground reference for the three conductors (Fig. 4), the net charge on each object is:

$$
\left[\begin{array}{l}
\mathrm{Q}_{1} \\
\mathrm{Q}_{2} \\
\mathrm{Q}_{3}
\end{array}\right]=\left[\begin{array}{ccc}
\mathrm{C}_{10}+\mathrm{C}_{12}+\mathrm{C}_{13} & -\mathrm{C}_{12} & -\mathrm{C}_{13} \\
-\mathrm{C}_{21} & \mathrm{C}_{20}+\mathrm{C}_{21}+\mathrm{C}_{23} & -\mathrm{C}_{23} \\
-\mathrm{C}_{31} & -\mathrm{C}_{31} & \mathrm{C}_{30}+\mathrm{C}_{31}+\mathrm{C}_{32}
\end{array}\right]\left[\begin{array}{c}
\mathrm{V}_{1} \\
\mathrm{~V}_{2} \\
\mathrm{~V}_{3}
\end{array}\right]
$$

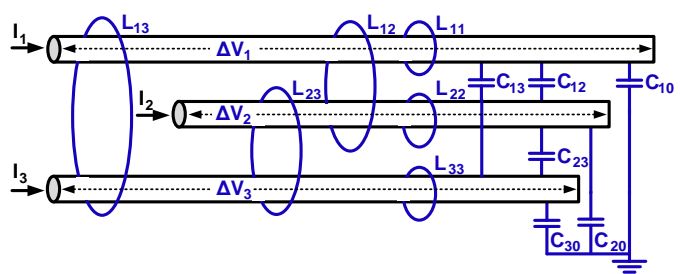

Fig. 4. Inductance/capacitance matrix configurations for a three disks winding.

Eqs. 3-10 briefly explain the electrostatic and magnetostatic analyses performed by the finite element to calculate various transformer parameters. More details about these analyses are available in [14-15]. Various winding deformations such as winding axial displacement, radial movement and disk space variation faults are simulated by moving the faulty winding/disk axially or horizontally by a specific percentage. Fig. 5 shows detailed finite element model of the transformer under various faults including geometric and magnetic flux distributions. Axial and radial faults are simulated by a small vertical $(\Delta \mathrm{h})$ and horizontal $(\Delta \mathrm{x})$ movement of the entire winding / disk, respectively [8-9, 16-25]. Disk space variation fault and core deformation are simulated by increasing the 
vertical distance between two adjacent disks (from $\mathrm{h}$ to $\mathrm{h}$ ') and changing transformer core structure, respectively.

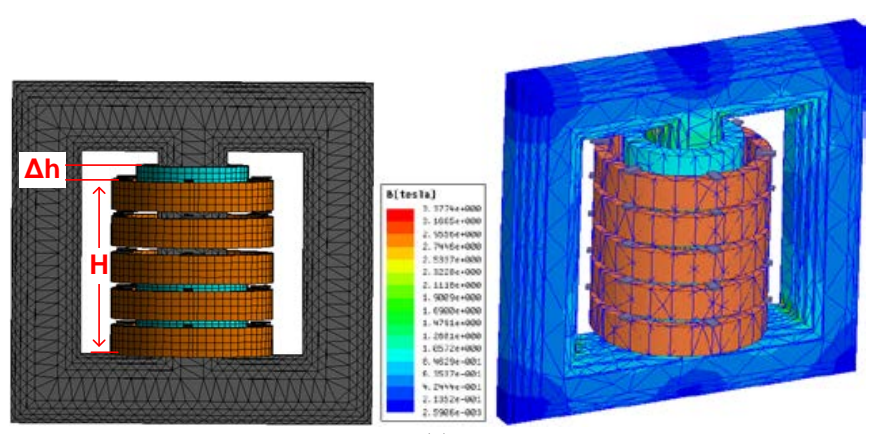

(a)

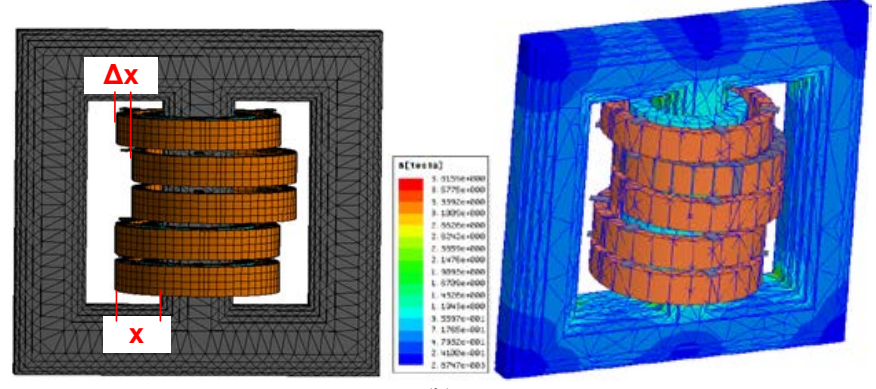

(b)

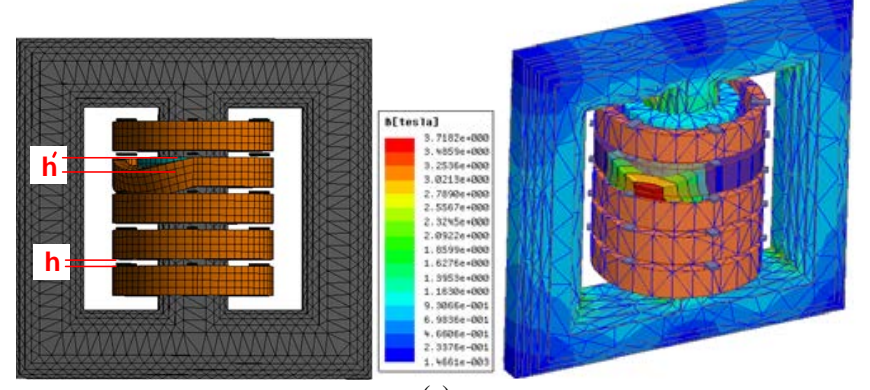

(c)

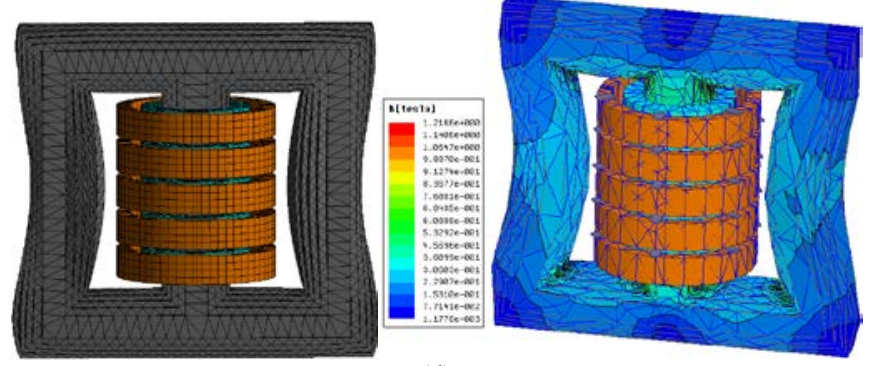

(d)

Fig. 5. Transformer three dimensional finite-element modelling geometry and flux distributions with internal faults; (a) axial displacement $\Delta \mathrm{h}$, (b) radial displacement $\Delta \mathrm{x}$, (c) disk space variation $\mathrm{h}$, (d) core deformation.

\section{Simulation Results}

The nonlinear finite element model of Fig. 3(b) is used to accurately simulate transformer operation subject to various internal faults under sinusoidal and non-sinusoidal (with harmonic phase angles of $0^{\circ}$ and $180^{\circ}$ ) operating conditions (Figs. 6-9). The $\Delta \mathrm{V}-\mathrm{I}$ locus is generated through energizing the HV winding with (non)sinusoidal voltage at power frequency $(50 \mathrm{~Hz})$ while the load is connected to the LV winding. The instantaneous values of $\mathrm{v}_{1}(\mathrm{t}), \mathrm{v}_{2}(\mathrm{t})$ and $\mathrm{i}_{1}(\mathrm{t})$ at time steps of $50 \mu$ s are measured to construct the $\Delta \mathrm{V}$-I locus of the healthy and faulty transformer conditions. It is worth mentioning that the load magnitude and PF do not have major impacts on the transformer $\Delta \mathrm{V}$-I locus locus as has been proved in [6].

\section{A. Winding Short Circuit Fault Considering Harmonics}

Studies show that about $80 \%$ of transformer breakdown are attributed to mechanical deformations [16-18] due to the short circuit faults. In the model under study, different number of windings has been short circuited and the $\Delta \mathrm{V}$-I locus is plotted and compared with the healthy locus as shown in Fig. 6 . According to Fig. 6(a), winding short circuit faults rotates the $\Delta \mathrm{V}$-I locus in clockwise direction with respect to the reference locus while a substantial increase in the entire area of the ellipse can be observed. The ellipse angle of rotation and its entire area increases with the increase of fault level. This is attributed to the fact that the entire transformer impedance is decreased when a winding short circuit takes place and, for the same input voltage (Fig. 6(a)), the input current increases.

Figs. 6 (b)-(e) compare the $\Delta \mathrm{V}$-I locus of healthy and faulty transformer with $5 \%$ and $10 \%$ short-circuited coils for nonsinusoidal excitation with $10 \%$ of $3^{\text {rd }}, 5^{\text {th }}$ and $7^{\text {th }}$ voltage harmonics at phase angles of $0^{\circ}$ and $180^{\circ}$. According to these figures, similar impact on the locus area and ellipse major axis rotation as in sinusoidal excitation can be noticed. However, the ellipse shape of the locus is distorted with minor peaky and flat loops depending on the order, magnitude and phase angle of the harmonics.

\section{B. Axial Displacement Fault Considering Harmonics}

This fault occurs due to the magnetic imbalance between the low and high voltage windings as a result of short circuit currents [19]. The axial displacement between the magnetic centers of the windings results in unbalanced magnetic force components in each half of the winding which leads to a change in its relative position [6]. This causes the impacted winding to shift axially with respect to the other winding.

Axial forces lead to tilting or bending of conductors and are known to be more destructive when the windings are not placed symmetrically [20]. Titling and bending of conductors between spacers are the most common reported deformations due to axial forces [21]. Furthermore, any small displacement during transformer transportation or due to earthquake would result in intensified axial forces when short circuit occurs [22]. Axial force due to the axial leakage flux at the gap between the two windings is calculated as [24]:

$\mathrm{F}_{\text {axial }}=2 \pi \mathrm{a}\left(\mathrm{NI}_{\max }\right)^{2}\left(\frac{\pi \mathrm{D}_{\mathrm{m}}}{\ell_{\text {eff }}}\right) \times 10^{-7}$

where a, $N, I_{\max }, D_{m}$ and $\ell_{\text {eff }}$ are fractional difference in winding heights, maximum current, mean diameter of the transformer limb (mm) and effective length of the path of the radial flux, respectively.

In the transformer model under study, axial fault is simulated by shifting the HV winding axially as shown in Fig. 5(a) [23]. Fig. 7 shows impact of two axial fault levels on the $\Delta \mathrm{V}$-I locus. As shown in Fig. 7(a), axial displacement slightly decreases the entire area of the locus while no rotation of the locus major axis is observed. This is attributed to the fact that axial displacement will slightly change the mutual inductance between the faulted winding and the adjacent winding. According to Figs. 7(b)-(e), similar comments apply for non- 
sinusoidal excitation of the transformer subject to axial displacement faults. However, the ellipse shape of the locus is distorted due to the generation of minor loops.

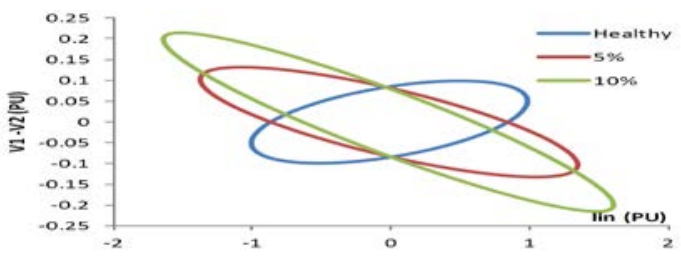

(a)

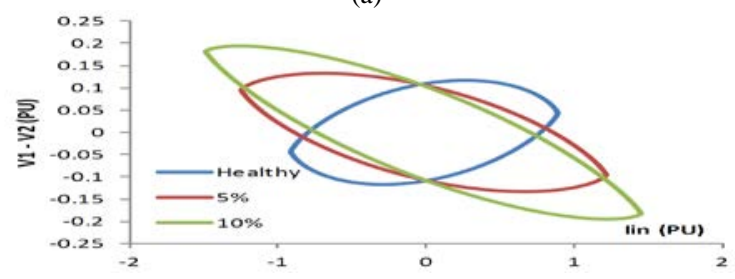

(b)

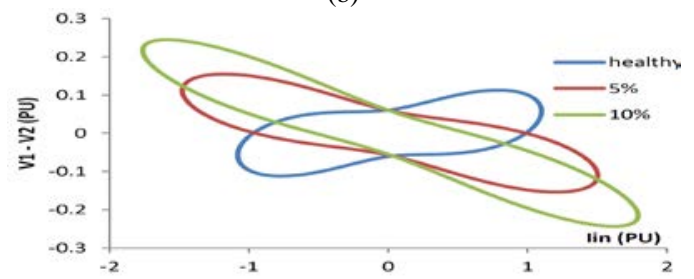

(c)

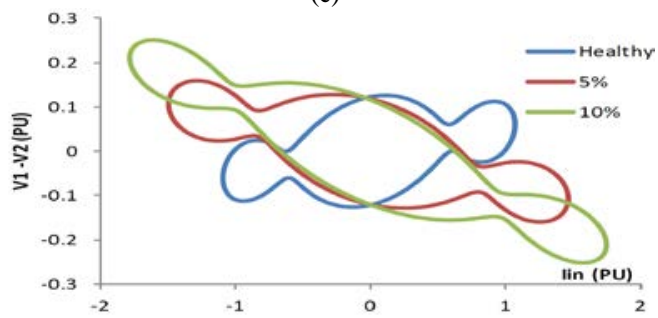

(d)

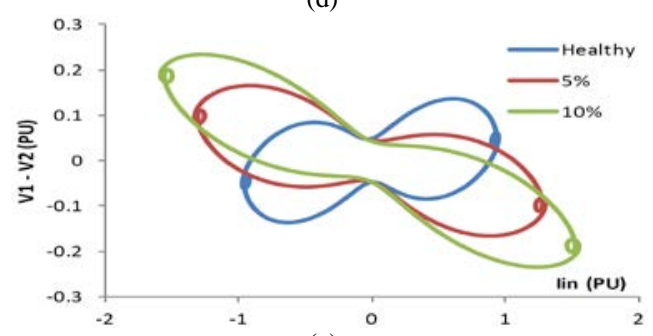

(e)

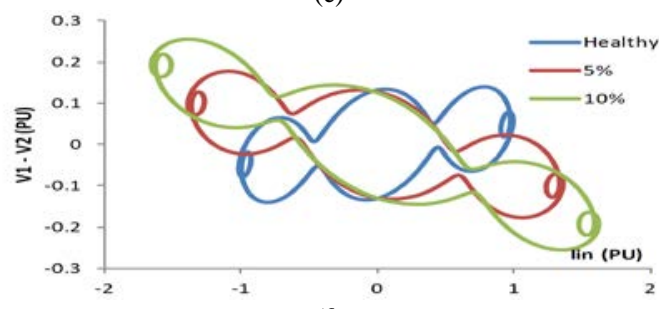

(f)

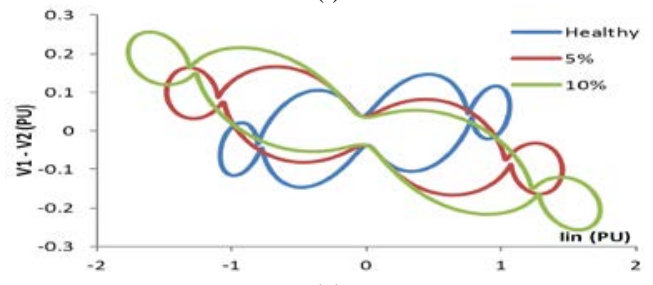

(g)

Fig. 6. Impact of short circuit fault on the online $\Delta \mathrm{V}$-I locus with sinusoidal excitation (a) and non-sinusoidal excitations consisting of fundamental and
$10 \%$ of the $3^{\text {rd }}(\mathrm{b}-\mathrm{c}), 5^{\text {th }}(\mathrm{d}-\mathrm{e})$ and $7^{\text {th }}(\mathrm{f}-\mathrm{g})$ harmonics with phase angles of $0^{\circ}$ and $180^{\circ}$.

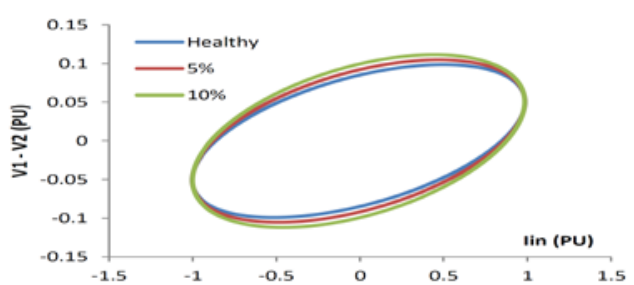

(a)

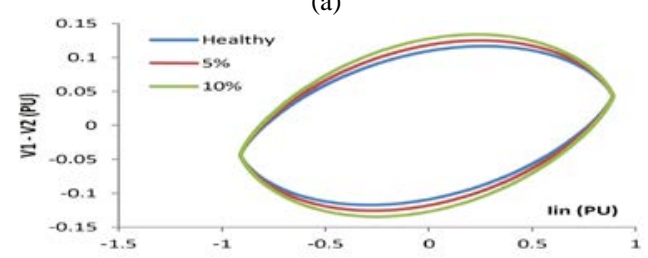

(b)

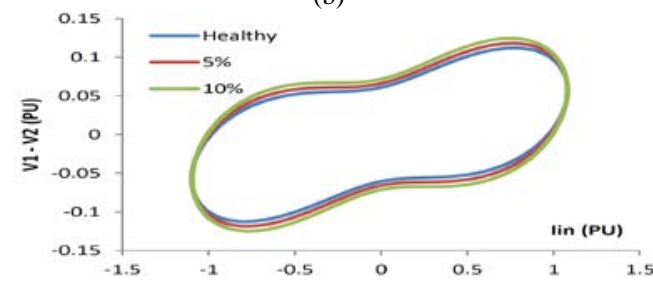

(c)

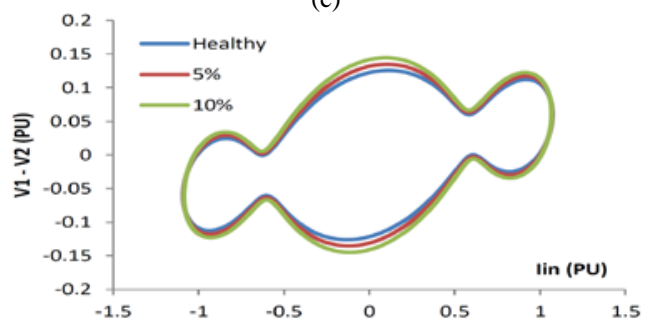

(d)

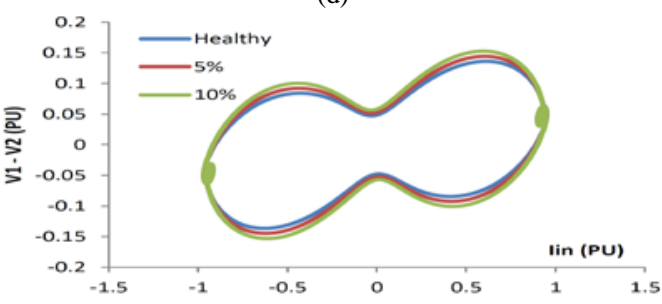

(e)

Fig. 7. Impact of axial displacement fault on the online $\Delta \mathrm{V}$-I locus with sinusoidal excitation (a) and non-sinusoidal excitations consisting of fundamental and $10 \%$ of the $3^{\text {rd }}(\mathrm{b}-\mathrm{c})$ and $5^{\text {th }}$ (d-e) harmonics with phase angles of $0^{\circ}$ and $180^{\circ}$.

\section{Radial Displacement Fault Considering Harmonics}

Interaction of leakage flux and windings current can cause radial electromagnetic forces that may cause the conductors to bend in each span or in alternate spans between the axial supporting strips [25]. Radial forces produced by the axial leakage field acting outwards on the outer winding can stretch the conductors, cause hoop stress and at the same time lead inner winding to experience radial compressive stress [25]. Radial force due to the axial leakage flux at the gap between the two windings is calculated as $[18,26]$ :

$\mathrm{F}_{\text {radial }}=\pi \mathrm{D}_{\text {ave }}\left(\frac{\sqrt{2} \mu_{0} \mathrm{NI}}{2 \mathrm{H}_{\mathrm{w}}}\right)(\sqrt{2} \mathrm{NI})$

where $H_{w}, D_{\text {ave }}, N, I$ and $\mu_{0}$ are respectively winding height, average winding diameter, number of turns, RMS winding's 
current and permeability of air. This force pulls the inner winding close to the core (buckling stress) while pushing the outer winding toward the limb (tensile stress) [27]. Various types of deformations due to radial forces have been discussed in the literature [28]. The most common classes of deformation are the free and forced buckling types. Radial fault may influence the entire windings or only a portion of the windings.

Fig. 8 shows the impact of radial movement of the HV disks as shown in Fig. 5(b) on the $\Delta \mathrm{V}$-I locus. According to Fig. 8(a), radial fault slightly decreases the locus area and rotates ellipse major axis clockwise direction. The impact is more pronounced as the fault level increases. The slight locus rotation discriminates this type of fault from the axial displacement fault.

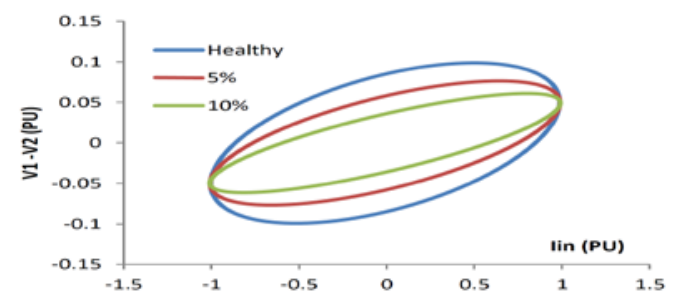

(a)

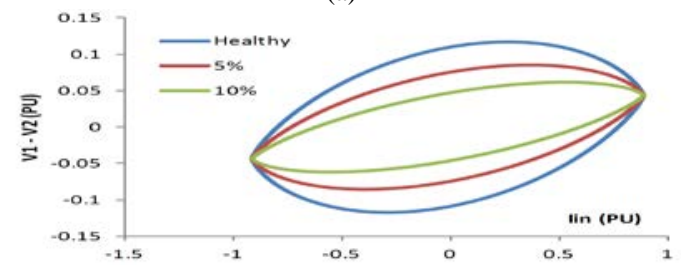

(b)

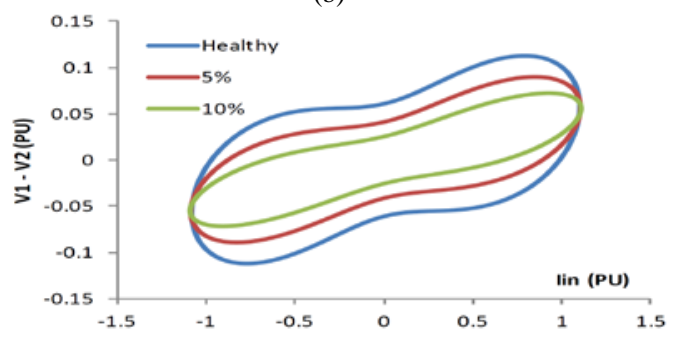

(c)

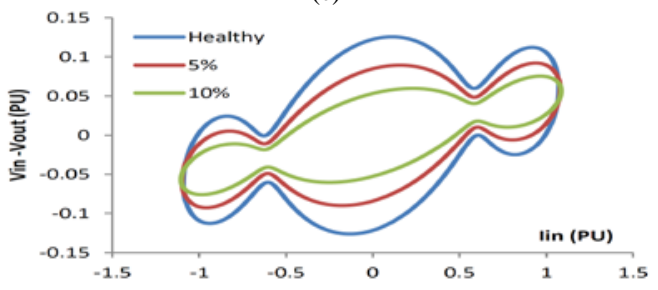

(d)

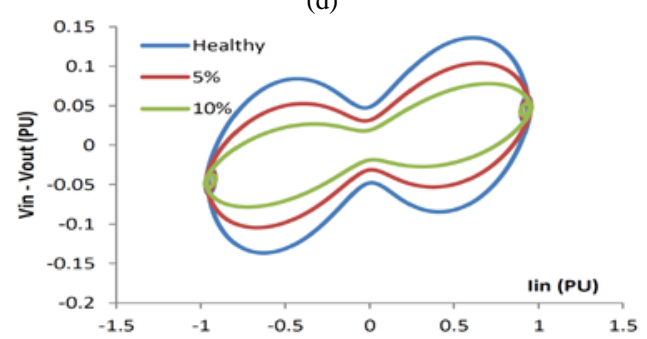

(e)

Fig. 8. Impact of radial displacement fault on $\Delta \mathrm{V}$-I locus with sinusoidal excitation (a) and non-sinusoidal excitations consisting of fundamental and $10 \%$ of the $3^{\text {rd }}(\mathrm{b}-\mathrm{c})$ and $5^{\text {th }}(\mathrm{d}-\mathrm{e})$ harmonics with phase angles of $0^{\circ}$ and $180^{\circ}$.
Similar comments apply for non-sinusoidal excitation (Figs. 8(b) - (e)) with the exception that ellipse locus contains minor loops. The level number, formations and magnitudes of the minor loops depend on the orders, magnitudes and phase angles of the voltage harmonics.

\section{Disk Space Variation Fault Considering Harmonics}

One of the frequently occurring mechanical faults in power transformers is the disk space variation [29-30] which changes the geometry of transformer windings as shown in Fig. 5(c).

Fig. 9 shows the impact of disk space variation fault on the $\Delta \mathrm{V}$-I locus with sinusoidal and non-sinusoidal excitations.
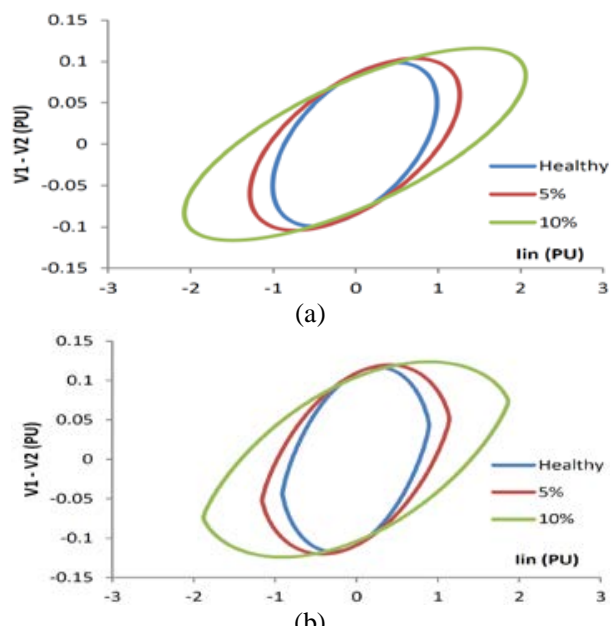

(b)
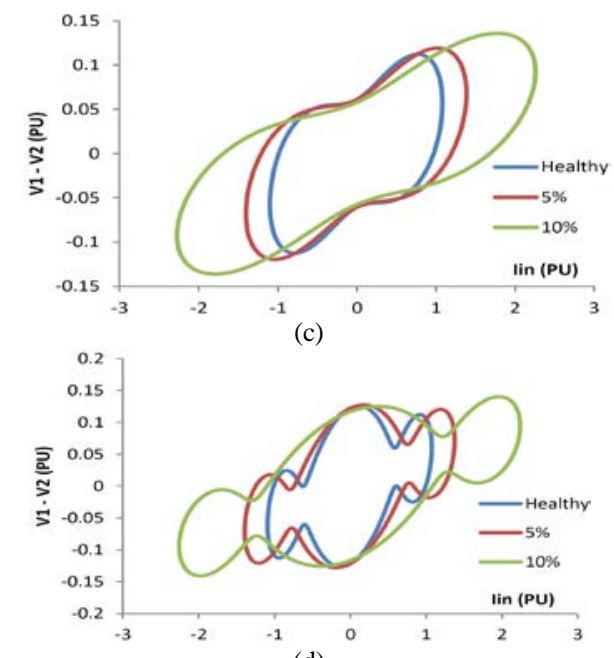

(d)

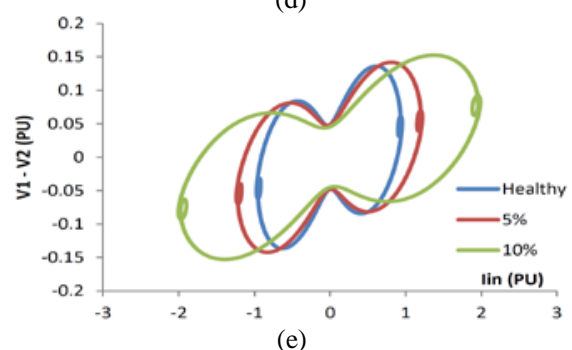

Fig. 9. Impact of disk space variation fault on the online $\Delta \mathrm{V}$-I locus with sinusoidal excitation (a) and non-sinusoidal excitations consisting of fundamental and $10 \%$ of the $3^{\text {rd }}(\mathrm{b}-\mathrm{c})$ and $5^{\text {th }}(\mathrm{d}-\mathrm{e})$ harmonics with phase angles of $0^{\circ}$ and $180^{\circ}$. 
Disk space variations fault without or with harmonics significantly rotates the $\Delta \mathrm{V}$-I locus in clockwise direction while increasing its entire area. Similar to short circuit, axial and radial faults, non-sinusoidal excitation of the transformer subject to disk space variation will also introduce minor loops in the $\Delta \mathrm{V}$-I locus (Figs. 9(b)-(e)).

\section{E. Core Deformation Fault Considering Harmonics}

Core deformation failures result in variations of the core's magnetic circuit (Fig. 5(d)). Core defects include shorted core laminations, burnt core laminations, multiple/unintentional core grounds, joint dislocations and lost core ground [31-33]. In addition, there are some core defects as a result of poor insulation of the core tightening screws or an obstructed oil cooling duct that causes excessive heat to the core. A poor or loose tightening between the core and the clamps of the windings can also cause damaging vibrations [31-33]. Fig. 10 shows the impact of core outer limbs deformation (as shown in Fig. 5(d)) on the $\Delta \mathrm{V}$-I locus with sinusoidal excitation. Fig. 10 shows that core deformation has a slight impact on the $\Delta \mathrm{V}$ I locus as it slightly increases its perimeter without introducing any rotation to the ellipse major axis. This slight impact is attributed to the fact that deformation of the outer limbs will affect the flux distribution in the vicinity of the transformer winding that in turns slightly changes the inductance of the windings.

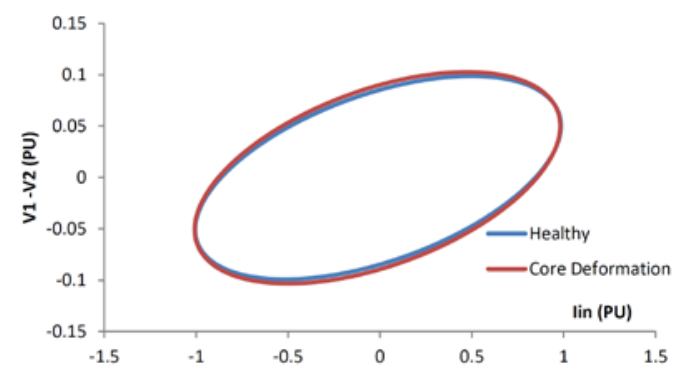

Fig. 10. Impact of core deformation fault (Fig. 5(d)) on the online $\Delta$ V-I locus with sinusoidal excitation.

\section{F. Impact of Load Level and Power Factor on $\triangle V$-I Locus}

According to [6], load level and PF have minor impacts on the proposed $\Delta \mathrm{V}$-I locus. To further investigate these impacts, simulations are performed and presented in Fig. 11 for resistive, series RL and parallel RC loads. As expected and reported in [6], load level and PF don't have significant impacts on the ellipse shape of the $\Delta \mathrm{V}$-I locus and will slightly change its area.

\section{ANALYSIS AND COMPARISON OF RESUlts}

Table I compares and summaries the impacts of the investigated internal winding faults (short circuit, axial, radial and disk space variation) on $\Delta \mathrm{V}$-I locus area and major axis rotation based on the detailed simulation results of Figs. 6-9. Ellipse entire area and the angle of ellipse major axis with the $\mathrm{x}$-axis have been calculated using an image processing-based Matlab code. The observations below can be drawn:

- Table I (rows 3-4, 13-14, 19-20, 25-26) confirms the previously reported $[6,18]$ impacts of internal winding faults for sinusoidal operation. However, results are more accurate as these references have used a distributed linear model to simulate faults by modifying circuit parameters while this paper utilizes an accurate nonlinear finiteelement transformer model to precisely simulate each fault.

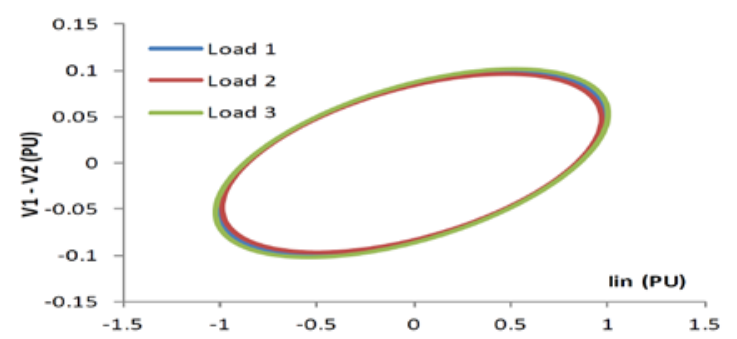

(a)

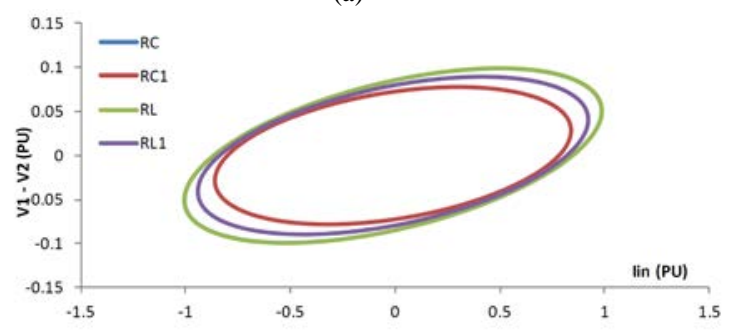

(b)

Fig. 11. Impacts of load type, level and PF on $\Delta \mathrm{V}$-I locus; (a) resistive loads, (b) inductive and capacitive loads.

- All observations about impacts of various faults on ellipse shape $\Delta \mathrm{V}$-I locus generally hold in presence of harmonics with the exception of the formation of minor loops.

- Harmonics and non-sinusoidal transformer excitations will influence the online fault detection approach by introducing minor loops in the ellipse $\Delta \mathrm{V}$-I locus. The numbers, magnitudes and type (peaky, flat) of the minor loops depend on the orders, magnitudes and phase angles of the voltage harmonics.

- According to Fig. 6 and Table I (rows 3-12), winding short circuit faults with (non)sinusoidal excitation result in clockwise rotation of the $\Delta \mathrm{V}$-I locus while substantially increasing its entire area. This is attributed to the fact that the entire transformer impedance is decreased when a winding short circuit takes place and as a result, for the same input voltage, the input current increases.

- According to Fig. 7 and Table I (rows 13-18), axial displacement faults with (non)sinusoidal transformer excitation slightly decrease $\Delta \mathrm{V}$-I locus area with no rotation of the major axis. This is expected as axial displacement slightly changes mutual inductance with respect to adjacent windings. This mutual inductance is usually smaller than winding self-inductance and its variations can be neglected.

- According to Fig. 8 and Table I (rows 19-24), radial faults with sinusoidal and non-sinusoidal transformer excitations decrease the locus area while slightly rotating the major axis. The slight locus rotation discriminates this type of fault from the winding axial fault.

- According to Fig. 9 and Table I (rows 25-30), disk space variations faults under sinusoidal and non-sinusoidal operating conditions significantly rotates the $\Delta \mathrm{V}$-I locus in clockwise direction while increasing its entire area. 
TABLE I

IMPACT OF FAULTS ON SHAPE, AREA AND AXIS ROTATION OF $\Delta$ V-I LOCUS CONSIDERING HARMONIC VOLTAGE DISTORTIONS.

\begin{tabular}{|c|c|c|c|c|c|c|c|c|}
\hline \multicolumn{2}{|c|}{ FAULT } & \multicolumn{3}{|c|}{ VOLTAGE HARMONIC } & \multicolumn{3}{|c|}{ ONLINE $\Delta$ V-I LOCUS (FIG. 2) } & \multirow[b]{2}{*}{$\begin{array}{c}\text { IMPACT OF FAULT ON } \\
\Delta V \text {-I LOCUS }\end{array}$} \\
\hline Type & $\begin{array}{l}\text { Level } \\
{[\%]^{*}}\end{array}$ & Order & $\begin{array}{c}\text { Mag } \\
{[\%]^{* *}}\end{array}$ & $\begin{array}{l}\text { Angle } \\
\text { [deg] }\end{array}$ & Shape & $\begin{array}{c}\text { Increase in } \\
\text { Area [\%] }]^{* * *}\end{array}$ & $\begin{array}{l}\text { Clockwise Rotation } \\
\text { of Major Axis [deg] }\end{array}$ & \\
\hline \multirow{14}{*}{$\begin{array}{l}\text { Short Circuit } \\
\text { (Fig. 6) }\end{array}$} & 5 & \multirow{2}{*}{\multicolumn{3}{|c|}{ Sinusoidal }} & \multirow{2}{*}{ Ellipse } & +44.41 & +33.48 & \multirow{14}{*}{$\begin{array}{c}\text { INCREASE } \\
\text { IN AREA } \\
+ \\
\text { SIGNIFICANT } \\
\text { CLOCKWISE ROTATION }\end{array}$} \\
\hline & 10 & & & & & +122.51 & +50.41 & \\
\hline & 5 & \multirow{4}{*}{3} & \multirow{4}{*}{10} & 0 & \multirow{2}{*}{$\begin{array}{l}\text { Ellipse with peaky } \\
\text { Minor Loops }\end{array}$} & +45.23 & +30.69 & \\
\hline & 10 & & & 0 & & +123.2 & +52.44 & \\
\hline & 5 & & & 180 & \multirow{2}{*}{$\begin{array}{l}\text { Ellipse with flat } \\
\text { Minor Loops }\end{array}$} & +43.22 & +30.46 & \\
\hline & 10 & & & 180 & & +117.5 & +51.90 & \\
\hline & 5 & \multirow{4}{*}{5} & \multirow{4}{*}{10} & 0 & \multirow{2}{*}{$\begin{array}{l}\text { Ellipse with peaky } \\
\text { Minor Loops }\end{array}$} & +44.8 & +30.68 & \\
\hline & 10 & & & 0 & & +123.5 & +52.23 & \\
\hline & 5 & & & 180 & Ellipse with flat & +42.48 & +26.87 & \\
\hline & 10 & & & 180 & Minor Loops & +117.3 & +54.04 & \\
\hline & 5 & \multirow{4}{*}{7} & \multirow{4}{*}{10} & 0 & \multirow{2}{*}{$\begin{array}{l}\text { Ellipse with peaky } \\
\text { Minor Loops }\end{array}$} & +43.53 & +25.2 & \\
\hline & 10 & & & 0 & & +119.1 & +55.3 & \\
\hline & 5 & & & 180 & Ellipse with flat & +42.1 & +24.53 & \\
\hline & 10 & & & 180 & Minor Loops & +118 & +53.2 & \\
\hline \multirow{10}{*}{$\begin{array}{l}\text { Axial } \\
\text { Displacement } \\
\text { (Fig. 7) }\end{array}$} & 5 & \multirow{6}{*}{3} & \multirow{6}{*}{ usoidal } & & Ellipse & -0.81 & -1.65 & \multirow{10}{*}{$\begin{array}{c}\text { SLIGHT DECREASE } \\
\text { IN AREA } \\
+ \\
\text { NO ROTATION }\end{array}$} \\
\hline & 10 & & & & Empse & -1.20 & -3.62 & \\
\hline & 5 & & & 0 & Ellipse with peaky & -0.35 & -0.83 & \\
\hline & 10 & & & 0 & Minor Loops & -0.45 & -0.64 & \\
\hline & 5 & & & 180 & Ellipse with flat & -0.22 & -0.12 & \\
\hline & 10 & & & 180 & Minor Loops & -0.32 & -1.35 & \\
\hline & 5 & & & 0 & Ellipse with peaky & -0.41 & -1.3 & \\
\hline & 10 & & & 0 & Minor Loops & -0.55 & -0.39 & \\
\hline & 5 & 5 & 10 & 180 & Ellipse with flat & -0.20 & +0.12 & \\
\hline & 10 & & & 180 & Minor Loops & -0.42 & -2.07 & \\
\hline & 5 & & nusoidal & & Ellipse & -10 & +0.03 & \\
\hline & 10 & & niusorud & & Empse & 34.1 & +3.81 & \\
\hline & 5 & & & 0 & Ellipse with peaky & -15.4 & +1.10 & \\
\hline Radial & 10 & & & 0 & Minor Loops & -32.7 & +4.56 & \\
\hline $\begin{array}{l}\text { Displacement } \\
\text { (Fig. 8) }\end{array}$ & 5 & 3 & 10 & 180 & Ellipse with flat & -10.9 & +2.70 & $\begin{array}{l}\text { DECREASE } \\
\text { IN AREA }\end{array}$ \\
\hline & 10 & & & 180 & Minor Loops & -42.8 & +3.90 & $\begin{array}{c}\text { IN AREA } \\
+\end{array}$ \\
\hline & 5 & & & 0 & Ellipse with peaky & -16.7 & +3.10 & SLIGHT ROTATION \\
\hline & 10 & & & 0 & Minor Loops & -47.9 & +3.6 & \\
\hline & 5 & 5 & 10 & 180 & Ellipse with flat & -13.8 & +4.12 & \\
\hline & 10 & & & 180 & Minor Loops & -43.4 & +4.90 & \\
\hline & 5 & & nusoidal & & Ellipse & +56.7 & +2.2 & \\
\hline & 10 & & nusoida & & Ellipse & +108.7 & +1.5 & \\
\hline & 5 & & & 0 & Ellipse with peaky & +58.3 & +1.3 & \\
\hline Disk Space & 10 & & & 0 & Minor Loops & +106.7 & +2.63 & SIGNIFICANT INCREASE \\
\hline Variation & 5 & 3 & 10 & 180 & Ellipse with flat & +52 & +0.76 & IN AREA \\
\hline (Fig. 9) & 10 & & & 180 & Minor Loops & +98 & +0.91 & + \\
\hline & 5 & & & 0 & Ellipse with peaky & +61 & +1.01 & CLOCKWISE ROTATION \\
\hline & 10 & & & 0 & Minor Loops & +117.2 & +0.89 & \\
\hline & 5 & 5 & 10 & 180 & Ellipse with flat & +58.5 & +1.71 & \\
\hline & 10 & & & 180 & Minor Loops & +107.9 & +2.76 & \\
\hline
\end{tabular}

*) Fault level in percentage of total windings; for example, $10 \%$ of axial, radial and disk space faults correspond to $\Delta \mathrm{h}=0.1 \mathrm{H}, \Delta \mathrm{x}=0.1 \mathrm{x}$ and $\mathrm{h}$ ' $=0.1 \mathrm{~h}$ in Fig. 5 . **) Percentage of individual voltage harmonics with respect to the fundamental voltage of $1 \mathrm{pu}$.

***) Percentage of increase in locus area and axial rotation with respect to no fault condition with/without harmonics.

- Industrial applications of the online $\Delta \mathrm{V}$-I fault detection technique on large in-service power transformers will be very practical since it does not call for any particular equipment as it will use the metering devices attached with most of power transformers. It is worth mentioning that the transformer protection schemes such as differential protection relays are not capable of detecting transformer internal faults. Differential relays have rapid response and are effective in isolating power transformers during transformer faults however, they are greatly desensitized so that they do not falsely trigger due to circuit breaker actions, capacitor bank switching, and transformer tap changing, as well as during energizing period of the transformer. This means that for a minor winding deformation, the differential relay would not potentially operate. The new online $\Delta \mathrm{V}$-I fault detection approach is meant to detect incipient winding deformation and it does not necessarily have to be used to trip the transformer. The proposed technique can be used as a flagship to alarm the control center that something is being wrong within the transformer winding mechanical structure so that an appropriate remedial action or further investigation can be made on a proper time to avoid catastrophic failures. 


\section{EXPERIMENTAL VALIDATION OF $\Delta$ V-I LOCUS FOR SHORT CIRCUIT FAULT AND (NON)SINUSOIDAL EXCITATION}

Further investigations of the online fault detection approach based on $\Delta \mathrm{V}$-I locus were carried out through experimental laboratory tests for the setup shown in Fig. 12 under sinusoidal and non-sinusoidal transformer excitations (Fig. 13).

The detailed technical setup shown in Fig. 12(b) consists of transformer, digital oscilloscope, power source, computer, Fluke digital multimeter, load and current sense resistor. The single-phase $2 \mathrm{kVA}, 220 / 110 \mathrm{~V}, 50 \mathrm{~Hz}$ test transformer has 9 tap positions at the secondary winding. The digital storage oscilloscope has four channels with bandwidth and sample rate resolution of $100 \mathrm{MHz}$ and $1.0 \mathrm{GS} / \mathrm{s}$, respectively. The AC and DC power source/analyser [34] is a programmable singlephase/three-phase, AC+DC $\left(7.5 \mathrm{~A}_{\text {rms }}\right.$ at $0-300 \mathrm{~V}_{\text {rms }}+4.88 \mathrm{~A}_{\mathrm{DC}}$ at $\left.0-400 \mathrm{~V}_{\mathrm{DC}}\right), 16-48000 \mathrm{~Hz}$ voltage source. The power source can generate non-sinusoidal voltages consisting of the fundamental and individual/simultaneous harmonic components with specified orders, magnitudes and phase angles. The accuracy/resolution of voltage, current, fundamental and harmonic frequencies are $0.5 \% / 0.01 \mathrm{~V}$, $0.5 \% / 0.01 \mathrm{~A}, 0.1 \% / 0.01 \mathrm{~Hz}$ and $0.5 \% / 0.1 \mathrm{~Hz}$, respectively.

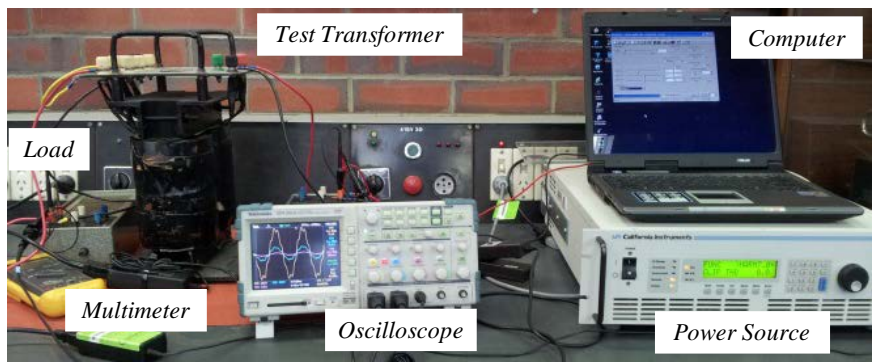

(a)

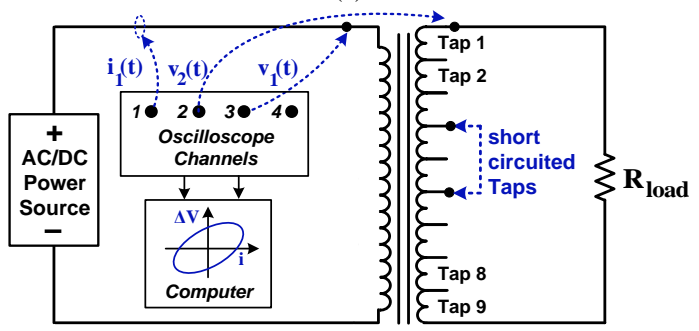

(b)

Fig. 12. (a) Experimental laboratory setup for a dry-type single-phase 2kVA, 220/110V, 50Hz test transformer, (b) Detailed technical setup.

For the experimental analysis of this paper, internal winding short circuit faults were created by short circuiting different numbers of transformer secondary taps while energizing the transformer with non-sinusoidal voltages. The non-sinusoidal input/output voltage and current waveforms were captured on the digital oscilloscope and processed on a computer to plot the corresponding $\Delta \mathrm{V}$-I locus. The validity of the online approach is examined by measuring the $\Delta \mathrm{V}$-I loci for three operating conditions.

The validity of the online approach under winding short circuit faults is examined by comparing the measured $\Delta \mathrm{V}$-I loci of the healthy and faulty transformer with a resistive load $\left(\mathrm{R}_{\mathrm{L}}=10 \Omega\right)$ under sinusoidal (Fig. 13(a)) and non-sinusoidal excitations.

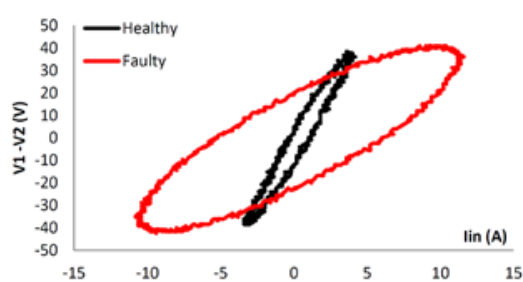

(a)

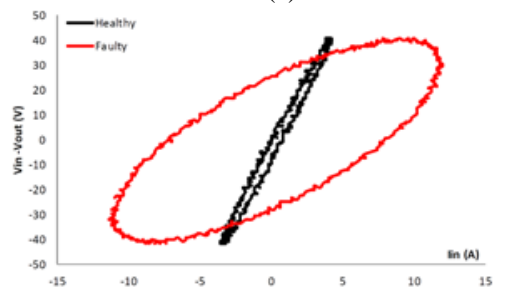

(b)

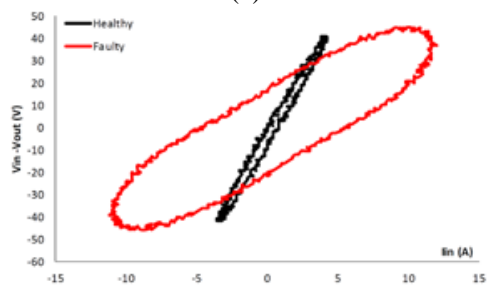

(c)

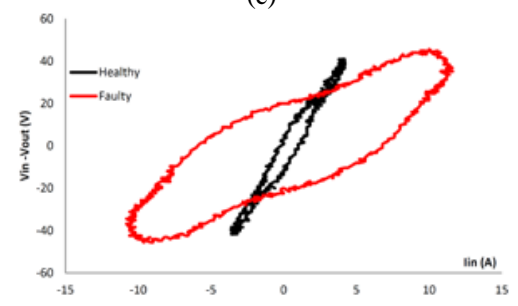

(d)

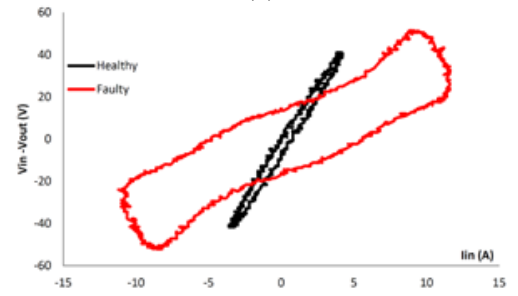

(e)

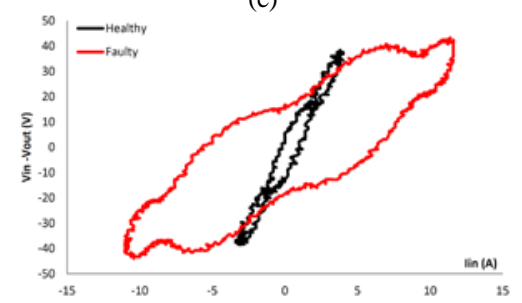

(f)

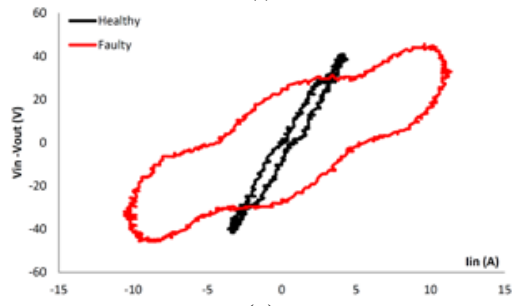

(g)

Fig. 13. Measured $\Delta \mathrm{V}$-I locus of the healthy and the faulty (winding short circuit) transformer with sinusoidal (a) and non-sinusoidal excitations including $10 \%$ voltage harmonics with phase angles of $0^{\circ}$ and $180^{\circ}$; (b)-(c) $3^{\text {rd }}$ harmonic, (d)-(e) $5^{\text {th }}$ harmonics, (f)-(g) $7^{\text {th }}$ harmonic. 
The validation is done for $10 \%$ of $3^{\text {rd }}$ (Figs. 13(b)-(c)), $5^{\text {th }}$ (Figs. 13(d)-(e)) and $7^{\text {th }}$ (Figs. 13(f)-(g)) voltage harmonics with phase angels of $0^{\circ}$ and $180^{\circ}$. These measurements clearly confirm the (distorted) ellipse shape of $\Delta \mathrm{V}$-I locus (Fig. 2) and the impact of winding short circuit faults presented by the simulation results of Fig. 6 and Table I (rows 3-16).

\section{CONCLUSION}

This paper presents detailed finite-element based simulations and analysis to evaluate the performance of an online internal transformer fault detection approach for sinusoidal and nonsinusoidal operating conditions. Based on extensive simulations and analyses for short circuit, axial, radial and disk space variation faults, as well as laboratory measurements for winding short circuit faults, the main conclusions are:

- Under sinusoidal operating conditions, the $\Delta \mathrm{V}$-I locus of the healthy/faulty transformer is an ellipse. Harmonics distort the shape of locus by introducing minor loops. The shape, magnitude and number of minor loops depend on the order, percentage and phase angle of harmonics.

- For sinusoidal and non-sinusoidal operating conditions, the $\Delta \mathrm{V}$-I locus of healthy transformer can be used as the fingerprint and can be continuously compared with the online measured locus to detect internal faults.

- Each fault impacts the $\Delta \mathrm{V}$-I locus shape, area and major axis rotation in a unique way with a certain degree of change that depends on the fault type and level, as well as harmonic order, magnitude and phase angle.

- In contrast to conventional off-line sweep frequency response techniques, the $\Delta \mathrm{V}$-I locus is conducted at the power frequency, does not require taking the transformer out of service and hence continuous online evaluations of transformer winding mechanical integrity can be realised.

- The online $\Delta \mathrm{V}$-I locus can identify and qualify transformer internal faults under (non)sinusoidal operating conditions. However, its application to practical three-phase power transformers has not been explored and requires more research.

- Impacts of nonlinear loads on the $\Delta \mathrm{V}$-I locus of transformer with (non)sinisoidal excitation depend on characteristics of the injected input voltage and output current harmonics at its terminals which are not investigated in this paper.

\section{APPENDIX}

TABLE A: DETAILS OF THE FINITE ELEMENT TRANSFORMER MODEL.

\begin{tabular}{|c|c|c|c|c|}
\hline \multicolumn{5}{|c|}{ SIMULATED TRANSFORMER PARAMETERS } \\
\hline $\mathrm{S} / \mathrm{f}$ & \multicolumn{2}{|c|}{ Rated pow / frequency } & \multicolumn{2}{|c|}{$5 \mathrm{kVA}, 50 \mathrm{~Hz}$} \\
\hline $\mathrm{V}_{\mathbf{H}} / \mathrm{V}_{\mathbf{L}}$ & \multicolumn{2}{|c|}{ Rated HV / LV voltage } & \multicolumn{2}{|c|}{$22 \mathrm{kV} / 11 \mathrm{kV}$} \\
\hline $\mathrm{N}_{\mathrm{P}} / \mathrm{N}_{\mathrm{S}}$ & \multicolumn{2}{|c|}{ Primary/secondary windings } & \multicolumn{2}{|c|}{$510 / 260$} \\
\hline $\mathrm{D}_{\mathrm{P}} / \mathrm{D}_{\mathrm{s}}$ & \multicolumn{2}{|c|}{ Primary/secondary disks } & \multicolumn{2}{|c|}{$200 / 100$} \\
\hline \multicolumn{5}{|c|}{ TRANSFORMER DIMENSIONS } \\
\hline \multirow{2}{*}{ Region } & \multirow{2}{*}{$\begin{array}{c}\text { Loss density } \\
{\left[\mathrm{W} / \mathrm{m}^{3}\right]}\end{array}$} & \multicolumn{3}{|c|}{ Dimensions [mm] } \\
\hline & & Height & Inner & Outer \\
\hline Core Window & 12800.12 & 1700 & & -- \\
\hline HV Winding & 36812.58 & 1700 & 722 & 835 \\
\hline LV Winding & 71510.13 & 1650 & 462 & 532 \\
\hline
\end{tabular}

\section{REFERENCES}

[1] "IEEE Guide for the Application and Interpretation of Frequency Response Analysis for Oil-Immersed Transformers," IEEE Std C57.1492012, pp. 1-72, 2013.

[2] A. Hyun-Mo, L. Ji-Yeon, K. Joong-Kyoung, O. Yeon-Ho, J. Sang-Yong, H. Sung-Chin, "Finite-element analysis of short-circuit electromagnetic force in power transformer," Industry Applications, IEEE Transactions on, vol. 47, pp. 1267-1272, 2011.

[3] M. Bigdeli, M. Vakilian, E. Rahimpour, D. Azizian, "Transformer winding diagnosis using comparison of transfer function coefficients," in Electrical Engineering/Electronics, Computer, Telecommunications and Information Technology (ECTI-CON), 2011 8th International Conference on, 2011, pp. 681-683.

[4] A. Abu-Siada, N. Hashemnia, S. Islam, M.A.S. Masoum, "Understanding power transformer frequency response analysis signatures," Electrical Insulation Magazine, IEEE, vol. 29, pp. 48-56, 2013.

[5] P. J. Baird, H. Herman, G. C. Stevens, P. N. Jarman, "Non-destructive measurement of the degradation of transformer insulating paper," Dielectrics and Electrical Insulation, IEEE Transactions on, vol. 13, pp. 309-318, 2006.

[6] A. Abu-siada S. Islam, "A novel online technique to detect power transformer winding faults," Power Delivery, IEEE Transactions on, vol. 27, pp. 849-857, 2012.

[7] N. Abeywickrama, Y.V. Serdyuk, S.M. Gubanski, "High-frequency modeling of power transformers for use in frequency response analysis ," Power Delivery, IEEE Transactions on, vol. 23, pp. 2042-2049, 2008.

[8] E. Rahimpour, M. Jabbari, S. Tenbohlen, "Mathematical comparison methods to assess transfer functions of transformers to detect different types of mechanical faults," Power Delivery, IEEE Transactions on, vol. 25, pp. 2544-2555, 2010.

[9] M. Bagheri, M.S. Naderi, T. Blackburn, T. Phung, "Practical challenges in online transformer winding deformation diagnostics," in Electric Power and Energy Conversion Systems (EPECS), 2011 2nd International Conference on, 2011, pp. 1-6.

[10] Ali S. Masoum, N. Hashemnia, A. Abu-Siada, M.A.S. Masoum, S. Islam "Finite-element performance evaluation of on-line transformer internal fault detection based on instantaneous voltage and current measurements", Australian Journal of Electrical and Electronic Engineering (AJEEE), Paper: E13-190.R2, In Press.

[11] A. Group, "Ansoft Maxwell," 16.0.0 ed. Australia Leading Engineering Application Providers Australia, 2013.

[12] O. Moreau, L. Popiel, L. Pages, "Proximity losses computation with a 2D complex permeability modelling", IEEE Transactions on Magnetic, vol. 34, no. 5, pp. 3636-3619, 1998.

[13] E. Bjerkan, H.K. Høidalen, "High frequency FEM-based power transformer modeling: investigation of internal stresses due to networkinitiated overvoltages," Electric Power Systems Research, vol. 77, pp. 1483-1489, 2007.

[14] Z. Haijun, Y. Bin, X. Weijie, W. Shuhong, W. Guolin, H. Youpeng, Z. Jingyin, "Dynamic deformation analysis of power transformer windings in short-circuit fault by FEM", IEEE Transactions on Applied Superconductivity, vol. 24, no. 3, pp. 1-4, 2014.

[15] E. Bjerkan, H.K. Høidalen,"Detailed high frequency power transformer modeling in ATP using FEM and Matlab," The European EMTPATP Conference, Oct. 3-5, 2004, pp. 1-4.

[16] D. Sharafi, "Life extension of a group of western power transformers," in Power and Energy Engineering Conference (APPEEC), 2010 AsiaPacific, pp. 1-4.

[17] S. Islam, "Detection of shorted turns and winding movements in large power transformers using frequency response analysis," in IEEE Power Engineering Society Winter Meeting, pp. 2233-2238 vol.3, 2000.

[18] M. Bagheri, M.S. Naderi,T. Blackburn, "Advanced transformer winding deformation diagnosis: moving from off-line to on-line," Dielectrics and Electrical Insulation, IEEE Transactions on, vol. 19, pp. 1860-1870, 2012.

[19] N. Abeywickrama, Y.V. Serdyuk, S.M. Gubanski, "Effect of core magnetization on frequency response analysis (FRA) of power transformers," Power Delivery, IEEE Transactions on, vol. 23, pp. 14321438, 2008.

[20] A. Shintemirov, W.H. Tang, Q.H. Wu, "Transformer winding condition assessment using frequency response analysis and evidential reasoning," Electric Power Applications, IET, vol. 4, pp. 198-212, 2010.

[21] W. Zhongdong, L. Jie, D.M. Sofian, "Interpretation of transformer FRA responses- Part I: Influence of winding structure," Power Delivery, IEEE Transactions on, vol. 24, pp. 703-710, 2009. 
[22] M.R. Feyzi, M. Sabahi, "Finite element analyses of short circuit forces power transformers with asymmetric conditions," in Industrial Electronics, 2008. ISIE 2008. IEEE International Symposium on, 2008, pp. 576-581.

[23] E. Rahimpour, J. Christian, K. Feser, H. Mohseni, "Transfer function method to diagnose axial displacement and radial deformation of transformer windings," Power Delivery, IEEE Transactions on, vol. 18, pp. 493-505, 2003.

[24] M.S.A. Minhas "Dynamic behavior of transformer winding under shortcircuits", $\mathrm{PhD}$ Thesis, Faculty of Engineering, University of the Witwatersrand, Johannesburg, Nov. 2007.

[25] E. Bjerkan, "High frequency modeling of power transformers stresses and diagnostics," Doctoral Thesis for the degree of Doctor Ingeniør, Trondheim, 2005.

[26] K. Pourhossein, G.B. Gharehpetian, E. Rahimpour, "Buckling severity diagnosis in power transformer windings using Euclidean Distance classifier," in Electrical Engineering (ICEE), 2011 19th Iranian Conference on, 2011, pp. 1-1.

[27] E. Billig, "Mechanical stresses in transformer windings," Electrical Engineers - Part II: Power Engineering, Journal of the Institution of, vol. 93, pp. 227-243, 1946.

[28] K. Ludwikowski, K. Siodla, W. Ziomek, "Investigation of transformer model winding deformation using sweep frequency response analysis," Dielectrics and Electrical Insulation, IEEE Transactions on, vol. 19, pp. 1957-1961, 2012.

[29] H. Firoozi, M. Kharezi, H. Rahimpour, M. Shams, "Transformer fault diagnosis using frequency response analysis - practical studies," in Power and Energy Engineering Conference (APPEEC), 2011 Asia-Pacific, 2011, pp. 1-4.

[30] E. Rahimpour, S. Tenbohlen, "Experimental and theoretical investigation of disc space variation in real high-voltage windings using transfer function method," Electric Power Applications, IET, vol. 4, pp. 451-461, 2010.

[31] J. Pleite, Gonza, x, C. lez, J. Vazquez, A. Lazaro, "Power transformer core fault diagnosis using frequency response analysis," Electrotechnical Conference, 2006; MELECON, 2006; IEEE Mediterranean, pp. 11261129, 2006.

[32] O. A. Mohammed, Z. Liu, S. Liu, N. Y. Abed, "Finite-element-based nonlinear physical model of iron-core transformers for dynamic simulations," Magnetics, IEEE Transactions on, vol. 42, pp. 1027-1030, 2006.

[33] S. Ji, Y. Luo, Y. Li, "Research on extraction technique of transformer core fundamental frequency vibration based on OLCM," Power Delivery, IEEE Transactions on, vol. 21, pp. 1981-1988, 2006.

[34] 2253iX AC and DC Power Source, User Manual, California Instruments, http://www.calinst.com/products/Compact_iX_Series/downlo ads/2253iX_User_Manual_6005-962-RvG.pdf

Ali S. Masoum received his B.S. and M.S. degrees in electrical power engineering and electrical utility engineering in 2010 and 2011 from Curtin University, Perth, Australia. He is currently working toward the Ph.D. degree in electrical engineering at Curtin University. He is a Graduate Electrical Engineer at Western Power, Perth Australia. His main interests are power quality, power protection, power transformers and renewable energy resources. He is a member of IEEE and IET.

Naser Hashemnia received BSc in Electrical Power Engineering from Yazd University, Iran in 2006 and Master of Electrical Utility Engineering from Curtin University, Perth, WA in 2010. He received a scholarship from the Cooperative Research Centre for Infrastructure and Asset Management in August 2011 to continue his posgrduate $\mathrm{PhD}$ study at Curtin University. His research interests include power transformer condition monitoring and application of artificial intelligence to power systems.

Ahmed Abu-Siada received his B.Sc. and M.Sc. degrees from Ain Shams University, Egypt and the $\mathrm{PhD}$ degree from Curtin University, Australia, all in Electrical Engineering. Currently he is a Senior Lecturer in the Department of Electrical and Computer Engineering at Curtin University. His research interests include power system stability, condition monitoring, power electronics and power quality. He is a senior member of IEEE and the vicechair of the IEEE Computation Intellegence Society, WA Chapter.

Mohammad A.S. Masoum (S'88-M'91-SM'05) received his B.S., M.S. and Ph.D. degrees in Electrical and Computer Engineering in 1983, 1985, and 1991, respectively, from the University of Colorado, USA. Currently, he is a Professor in the Electrical and Computer Engineering Department, Curtin
University, Australia. Dr. Masoum is the co-author of Power Quality in Power Systems and Electrical Machines (Elsevier, 2008) and Power Conversion of Renewable Energy Systems (Springer, 2011).

Syed Islam received the B.Sc. from Bangladesh University of Engineering and Technology, Bangladesh, and the M.Sc. and PhD degrees from King Fahd University of Petroleum and Minerals, Saudi Arabia, all in electrical power engineering, in 1979, 1983, and 1988 respectively. He is currently the Chair Professor in Electrical Power Engineering at Curtin University, Australia. He is an Editor of the IEEE Transaction on Sustainable Energy. 